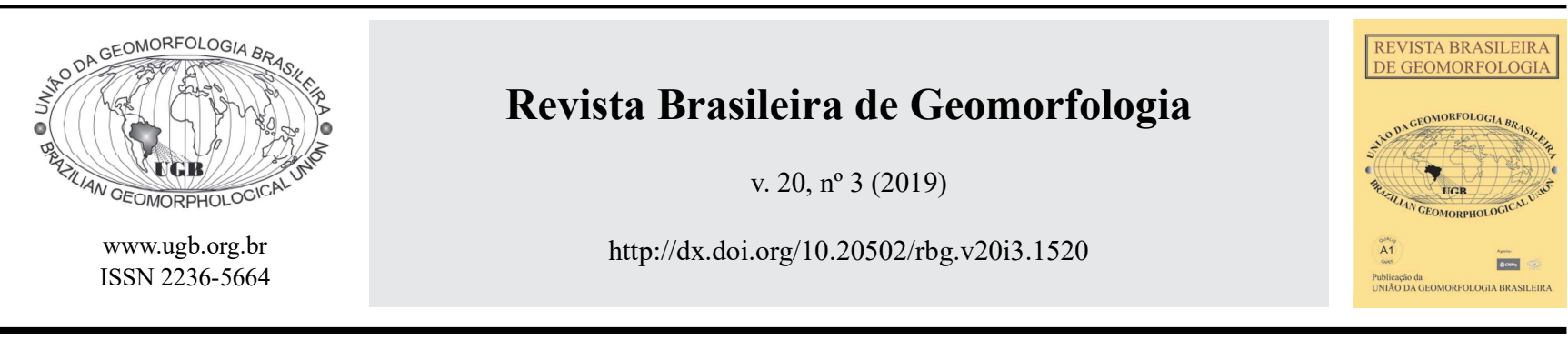

NOTA TÉCNICA

\title{
EVIDÊNCIAS DE REARRANJOS FLUVIAIS NO INTERFLÚVIO AMAZONAS-ESSEQUIBO - AMAZÔNIA SETENTRIONAL
}

\section{EVIDENCE OF FLUVIAL REARRANGEMENTS IN THE AMAZONAS- ESSEQUIBO INTERFLUVE - NORTHERN AMAZON}

Franzmiller Almeida Nascimento

Departamento de Geografia, Universidade Federal de Minas Gerais Av. Antônio Carlos, 6.627, Belo Horizonte, Minas Gerais. CEP: 31270-901. Brasil

ORCID:0000-0003-1063-0439

E-mail: franzmiller.nascimento@ufrr.br

André Augusto Rodrigues Salgado

Departamento de Geografia, Universidade Federal de Minas Gerais Av. Antônio Carlos, 6.627, Belo Horizonte, Minas Gerais. CEP: 31270-901. Brasil

ORCID:0000-0001-7679-5944

E-mail: aarsalgadoufmg@gmail.com

António Alberto Teixeira Gomes

CEGOT - Departamento de Geografia, Universidade do Porto Via Panorâmica, s/n, Porto. CEP: 4150-564. Portugal ORCID:0000-0002-1764-0659

E-mail:albgomes@gmail.com

\section{Informações sobre o Artigo}

Recebido (Received):

19/09/2018

Aceito (Accepted):

08/10/2018

\section{Palavras-chave:}

Capturas Fluviais; Bacia

Amazônica; Mapeamento

Geomorfológico.

\section{Keywords:}

River Capture; Amazon Basin; Geomorphological Mapping.

\section{Resumo:}

A região Amazônica, entre diversos fatores, destaca-se por apresentar um mosaico de paisagens, inseridas no grande sistema fluvial do rio Amazonas. No entanto, a porção setentrional desta região ainda necessita de um aprofundamento em estudos, principalmente em caráter geológico/geomorfológico. Neste contexto, a bacia hidrográfica do rio Branco - localizada no Estado de Roraima/Brasil, que drena em direção ao rio Amazonas, mas se localiza no tríplice divisor hidrográfico com as dos rios Orenoco (Venezuela) e Essequibo (Guiana) - apresenta evidências de rearranjo de drenagens em diversos de seus tributários, assim como ocorre no rio Maú, extremo nordeste da área, no interflúvio entre as bacias do Amazonas e Essequibo. Portanto, este estudo tem como objetivo a interpretação de evidências de rearranjo de drenagem, no médio/baixo curso do rio Maú, tais como capturas fluviais e depósitos aluvionares, por meio de análises em imagens de sensoriamento remoto e dados morfométricos obtidos de MDE's. Os procedimentos de análise 
basearam-se na interpretação de imagens de sensoriamento remoto do satélite SENTINEL-2, 10x10 metros, sensor MSI, em conjunto com dados morfométricos obtidos dos MDE's ALOS/PALSAR, 12,5x12,5 metros e SRTM/ TOPODATA, 30x30 metros, afim de analisar a rede de drenagem, feições morfológicas e depósitos aluvionares. Os dados interpretados indicam que o sistema fluvial do médio/baixo curso do rio Maú possuía pouca ação erosiva, pois seu nível de base regional permitiu o transbordamento lateral e a formação da rede de paleocanais distributários, constituindo feições de leques aluvionares, sendo estes canais afluentes do rio Rupununi (bacia do Essequibo). Posteriormente, em decorrência de uma aparente mudança no nível de base regional do rio Branco, favoreceu a captura do rio Maú para a Bacia Hirográfica Amazônica, reorganizando os sistemas de drenagem local e consequentemente, promovendo mudanças na paisagem. Tais conclusões abrem espaço para estudos futuros que visem datar os depósitos sedimentares e assim remontar a idade dos sistemas de leques e da captura da região drenada pelo rio Maú para a bacia Amazônica.

\begin{abstract}
:
The Amazon region stands out, among several reasons, for presenting a mosaic of landscapes in the Amazon River's large fluvial system. However, studies about the northern portion of this region still lack in depth, mainly in geology and geomorphology. In this context, the Branco River basin - located in the State of Roraima, in Brazil, which drains towards the Amazon River but is located in the triple hydrographic divisor with those of the rivers Orinoco (Venezuela) and Essequibo (Guiana) - presents evidence of drainage rearrangement in several of its tributaries, as occurs with the Maú River in the far northeast of the area, at the interflow between the Amazonas and Essequibo basins. Therefore, this study aims to interpret evidence of drainage rearrangement in Maú River's medium/low course, such as river capture and alluvial deposits, by means of remote sensing images and morphometric data obtained from DEM's. The analysis procedures were based on the interpretation of remote sensing images of the satellite SENTINEL-2, 10x10 meters, MSI sensor, together with morphometric data obtained from the MDE's ALOS/PALSAR, 12.5x12.5 meters and SRTM/TOPODATA, 30x30 meters, in order to analyze the drainage network, morphological features and alluvial deposits. The interpreted data indicate that the fluvial system of Maú River's medium/low course suffered little erosion because its regional base level had allowed lateral overflow and formation of a network of distributary paleochannels, constituting features of alluvial fans; the channels being tributaries of the Rupununi River (Essequibo Basin). Subsequently, a change in the regional base level of the Branco River apparently favored the capture of Maú River for the Amazon Hydrographic Basin, reorganizing the local drainage systems and, consequently, promoting changes in the landscape. These conclusions clear the path for future studies that aim to assess the dates of the sedimentary deposits and thus track down the age of the fan systems and the capture of the area drained by the Maú River into the Amazon basin.
\end{abstract}

\section{Introdução}

Capturas fluviais permitem interpretar processos de rearranjo de drenagem que, por sua vez, constituem elemento chave para a morfogênese de diversas regiões do globo. Para Bishop (1995), os rearranjos na rede de drenagem podem estar condicionados a mudanças no nível de base regional e permitem que drenagens próximas, uma vez conectadas, reorganizem-se formando novos sistemas fluviais. Em geral as capturas fluviais alteram profundamente a morfodinâmica, pois implementam um novo nível de base. Este processo, leva ao rebaixamento das vertentes, favorecendo a mudança na morfodinâmica das bacias capturadas, transferência parcial ou total do fluxo de um rio para outro, rearran- jo de drenagem e, por vezes, profundas alterações na paisagem (SUMMERFIELD, 1991; BISHOP, 1995; PEDERSON, 2001; HUGGETT, 2007; PRINCE et al., 2010).

A região Amazônica, entre diversos fatores, se destaca pelo seu mosaico de paisagens inserido no grande sistema fluvial do rio Amazonas (GUPTA, 2007; STEVAUX e LATRUBESSE, 2017). No entanto, a porção setentrional desta região ainda é pouco estudada, principalmente a bacia hidrográfica do rio Branco - localizada no Estado de Roraima/Brasil - que drena em direção ao rio Amazonas, mas se localiza no tríplice limite desta com as dos rios Orenoco (Venezuela) e Essequibo (Guiana) (Figura 1). Segundo Guerra (1957); Berrangé (1975); Schaefer e Dalrymple (1996); 
Cremon et al. (2016), há indícios de que o setor norte da bacia do rio Branco teria um curso preferencial em sentido SW-NE, em direção ao mar do caribe, formando a bacia de drenagem denominada Proto-Berbice. Para estes autores, durante o Quaternário inicial, a rede de drenagem desta região foi reorganizada graças a uma captura fluvial. Esta reorganização das drenagens teria favorecido o direcionamento do atual curso do rio Branco para o rio Amazonas e proporcionado uma nova configuração no relevo regional.

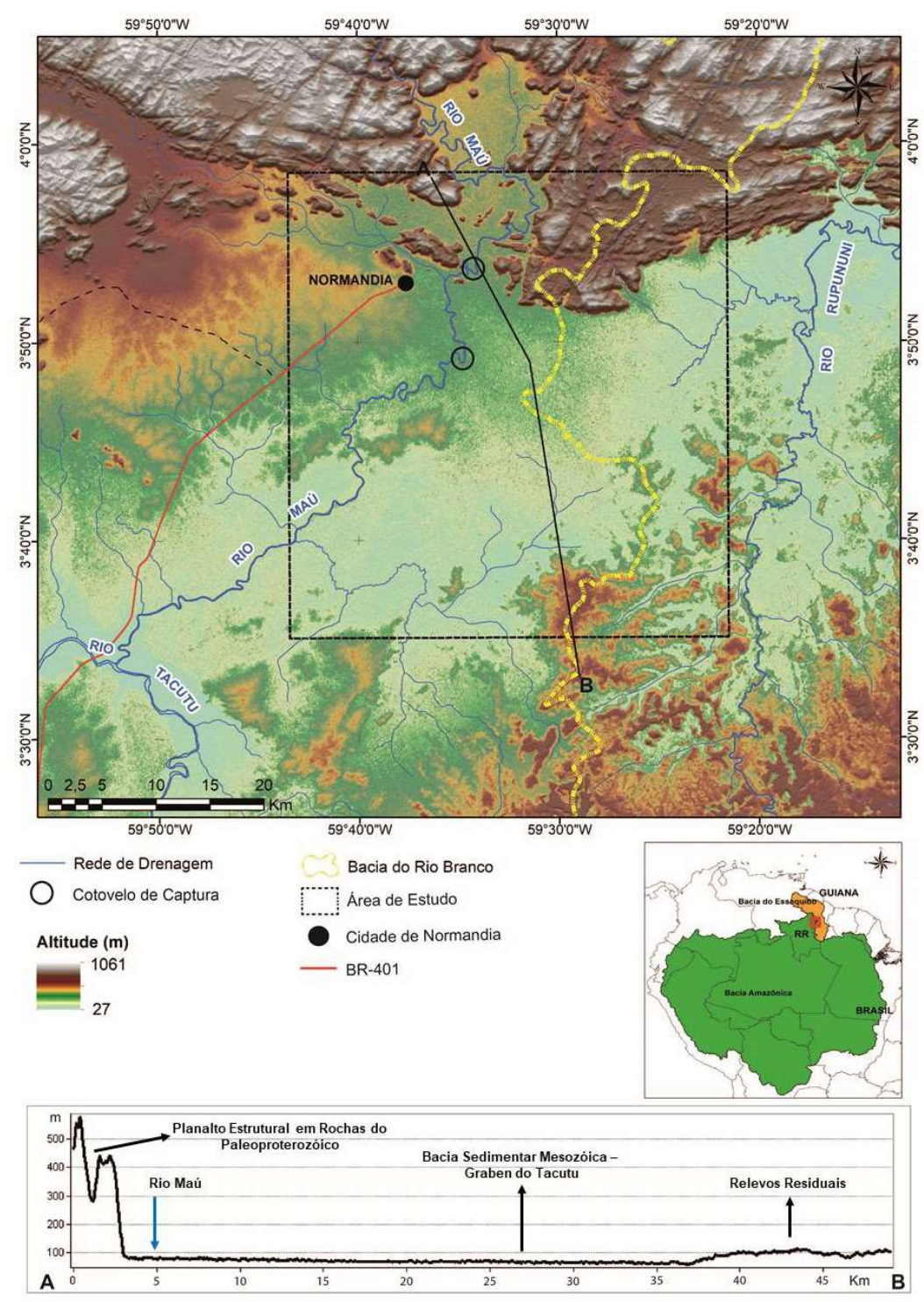

Figura 1 - Localização da área de estudo, integrado com a topografia do terreno elaborado a partir do MDE ALOS, compreendendo os compartimentos de relevo da área de estudo e sua localização entre o divisor hidrográfico Amazona/Essequibo, no norte de Roraima. Detalhe para perfil topográfica A-B, apresentando as morfologia locais, com exegero vertical 3,5x.

Considerando-se que a existência desta captura nunca efetivamente foi comprovada e que a mesma, se evidenciada, é um fato maior na evolução paleogeográfica da bacia Amazônica, torna-se importante realizar investigações que, através de sensoriamento remoto, geoprocessamento e trabalhos de campo, comprovem, ou não, a existência deste rearranjo de drenagem. Neste contexto, insere-se o presente estudo que utilizará de ferramentas de sensoriamento remoto para investigar essa possibilidade de rearranjo da rede de drenagem.

\section{Caracterização da Área de Estudo}

A área de estudo desta pesquisa está localizada nas proximidades da cidade de Normandia, extremo 
nordeste de Roraima, no quadrante de coordenadas geográficas $59^{\circ} 20^{\prime}$ e $59^{\circ} 50^{\prime}$ de longitude oeste e $03^{\circ} 30^{\prime}$ e $04^{\circ} 00^{\prime}$ de latitude norte (Figura 1). O setor de ocorrência das feições observadas abrange uma área com $1.762,07 \mathrm{~km}^{2}$ (Figura 1).

O baixo/médio curso do rio Maú, assim como o divisor hidrográfico das bacias do rio Branco/Essequibo estão inseridos no contexto geológico regional de ambiente intracratônico, que corresponde aos terrenos da porção norte do Cratôn Amazônico, no Escudo das Guianas (ALMEIDA et al., 1978; CORDANI et al. 1997; HASUI et al. 1984; TASSINARI e MACAMBIRA 2004). A área de estudo abrange a porção a NE do domínio Surumu, limitando-se com o contato Graben do Tacutu. O Grupo Surumu consiste em dacitos, riodacitos e andesitos, intrudidos por monzo a sienogranitos e granodioritos (CPRM, 1999; REIS et al., 2000; REIS et al., 2003; MARZOLI et al., 1999). Já ao sul, uma extensa área aplainada é sustentada por sedimentos mezozóicos depositados no Graben do Tacutun (CPRM, 1999). Segundo Costa et al. (1991); Hahn et al. (2011), Nascimento (2016), esta estrutura representa um seguimento distensivo correspondente a um rift aulocógeno intracontinental implantado no Mesozóico, numa zona de reativação do cráton amazônico pertencente ao domínio litoestrutural Cinturão Guiana Central. Esta região apresenta feições estruturais orientadas preferencialmente na direção NE-SW (CPRM, 1999; REIS, 2003) e é rica em depósitos quartzarenicos neogenicos de origem eólica e ao longo das drenagens ocorrem depósitos aluvionares (CPRM, 1999).

$\mathrm{Na}$ área de estudo o relevo pode ser subdividido em três porções que apresentam evidente controle litoestrutural: i) um Planalto localizado no interflúvio Amazonas-Orenoco; ii) uma depressão aplainada no entorno da cidade brasileira de Boa Vista e; iii) a Planície Amazônica, margeando os canais fluviais (IBGE, 2005; COSTA, 2008; BESERRANETA e TAVARES JÚNIOR, 2008). Ao norte, a primeira das unidades constituiu um relevo dissecado em cristas alongadas e pontões com encostas ravinadas e vales profundos, estruturada em rochas vulcano-plutônicas proterzóicas e falhas preferenciais ENE-WSW e E-W. Este relevo apresenta uma variação altimétrica de 250 a 1.000 metros (Figura 1). Ao sul, a depressão corresponde a um modelo de acumulação (agradação), constituindo uma extensa região plana, com suave variação altimétrica, entre 60 a 100 metros. Estes terrenos são sustentados por superfícies neogênicas Formação Boa Vista e Formação Areais Brancas, que entulham a bacia mesozoica do Tacutu (CPRM, 1999). A Planície Amazônica é definida por ser uma morfologia de acumulação, formada por sedimentos areno-argilosos holocênicos, com influência direta do regime hidrológico dos principais cursos fluviais (IBGE, 2005).

O clima característico é tipo climático "Aw", tropical sub-úmido, com estações sazonais bem definidas, sendo o período seco ocorrendo de setembro a março e o período úmido, de abril a agosto. Os valores de precipitação anuais média são de $1.600 \mathrm{~mm}$., com temperatura média anual $28^{\circ} \mathrm{C}$ (BARBOSA, 1997; EVANGELISTA et al. 2008). A vegetação característica são as savanas gramíneos-lenhosas que distribuem nos relevos aplainados e suaves e nos altos planaltos, tendo como fitotipo vegetação arbustiva, árvores de pequeno porte e gramíneas. Nas encostas montanhosas, ocorre o predomínio de Floresta Ombrófila submontada (SILVA, 1997).

\section{Procedimentos Metodológicos}

O procedimentos metodológicos basearam-se em duas etapas: i) interpretação geomorfológica de feições em imagens de sensoriamento remoto associado a dados morfométricos obtidos em Modelos Digitais de Elevação (MDE's) e ii) mapeamento de feições morfológicas referentes a depósitos e leques aluvionares.

Para a interpretação de imagens de sensoriamento remoto e levantamento de dados morfométricos, utilizaram-se as imagens ópticas do satélite SENTINEL-2, sensor MSI, com resolução espacial de 10x10 metros, fornecida pela Agencia Espacial Européia (ESA). Em conjunto com estas imagens, foi utilizado o MDE-SRTM (RABUS et al. 2003) re-amostrado espacialmente para a resolução de $30 \times 30$ metros, fornecido pelo banco de dados geomorfométricos TOPODATA/INPE (VALERIANO, 2008). Associado a estes dados utilizou-se o MDE adquirido pelo satélite ALOS, resolução espacial 12,5 x 12,5 metros, fornecido pela Agência Epacial Norte Americana-NASA. Os dados obtidos através da manipulação do MDE foram associados com o banco de dados fornecido pelo site Planet.com, auxiliado pela ferramenta Google Earth PRO.

A interpretação geomorfológica das feições de rearranjo de drenagem e de depósitos aluvionares se deu de acordo com os modelos propostos por Nichols e Fisher (2007); Nichols (2009); Chakraborty e Ghosh (2010); Cremon et al. (2016) que consistem na interpretação de canais de drenagem, morfologias associadas ao trabalho dos rios e comparações com perfis topográficos transversais, no entendimento da evolução de leques aluvionares. Todos estes processos foram realizados em ambiente de Sistema de Informação Geográfica (SIG'S), utilizando o software ArcGis Desktop, v 10.5. 


\section{Resultados e Discussões}

O canal principal do rio Maú percorre, em seu alto curso, os relevos dissecados do Planalto do Interflúvio Amazonas-Orenoco (IBGE, 2005; COSTA, 2008). À medida que este penetra os relevos aplainados da Depressão de Boa Vista, sua competência é diminuída (IBGE, 2005; BESERRA NETA e TAVARES JÚNIOR, 2008) passando a divagar na planície, formando depósitos arenosos como barra de pontal, lagos periféricos e meandros abandonados. É possível notar que cotovelos estão associados a estes depósitos de barras e que, paralelamente, ocorrem paleocanais de drenagem que se estendem ao longo da planície adjacente (Figura 2). Estes se estendem por uma área que alcança mais de $25 \mathrm{~km}$ de extensão por $32 \mathrm{~km}$ de largura e formam uma complexa rede secundária, interligada por áreas abaciadas e lagos intermitentes, que correm perpendiculares ao sentido do canal principal do rio Maú. São evidenciados dois cotovelos no qual se forma feições de paleocanais distributivos, espraiando-se em direção a leste formando novas ramificações de canais que aparentam conexão com canal tributário do rio Rupununi, na bacia caribenha do Essequibo (Figura 2).

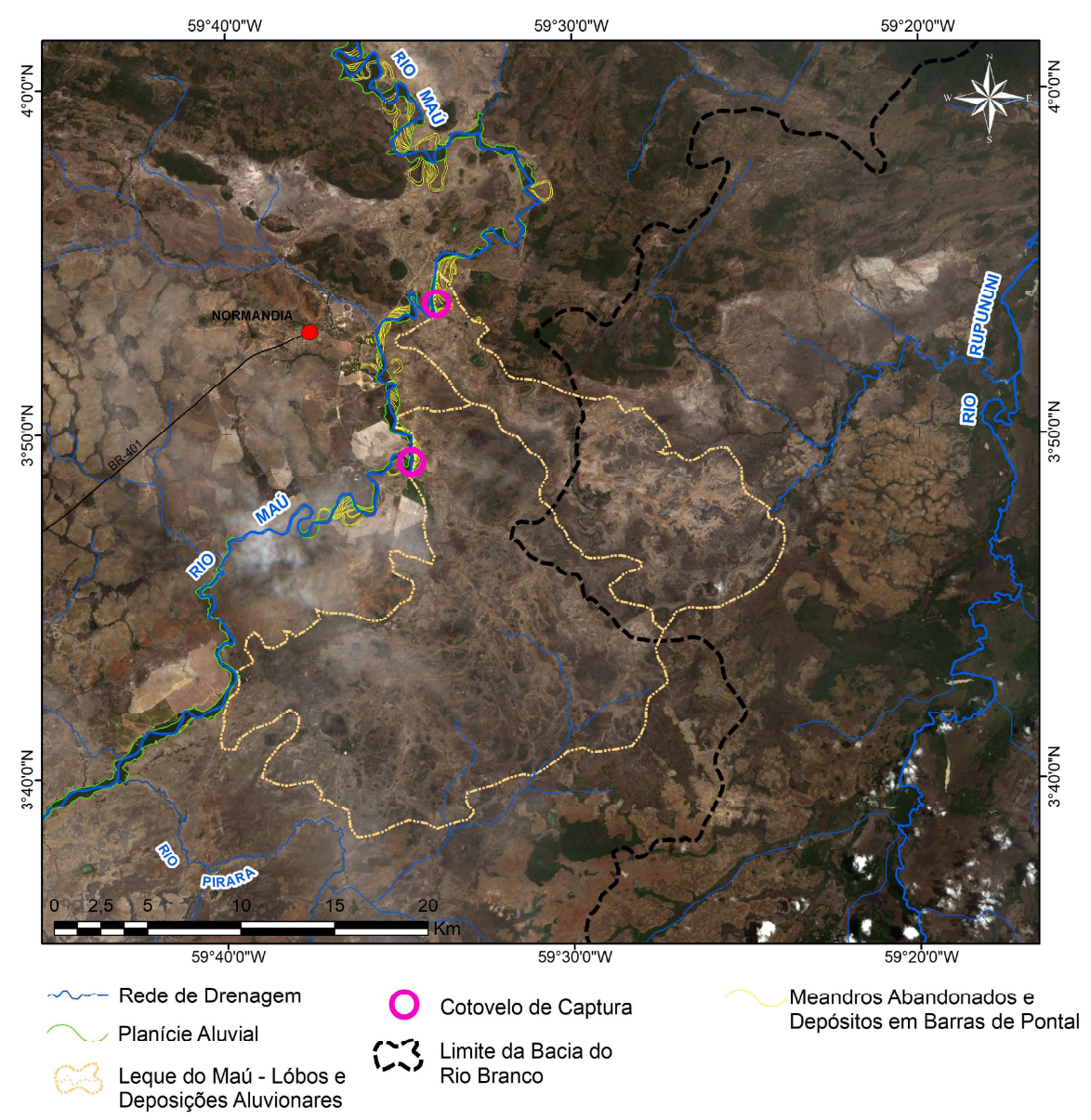

Figura 2 - Dado SENTINEL-2, com o detalhamento da feição geomorfológica do leque do rio Maú, com detalhe na rede paleocanais abandonados e morfologias de lóbos de deposição aluvionar.

Estes fatos indicam que o sistema fluvial do médio/ baixo curso do rio Maú possuía pouca ação erosiva, pois seu nível de base regional permitiu o transbordamento lateral e a formação da rede de paleocanais distributários constituindo uma feição de leque aluvionar. Além disso, os paleocanais identificados (Figura 2) apontam para uma paleoconexão entre o canal anterior do rio Maú e a rede de drenagem da bacia do rio Essequibo.
Estes dados corroboram com os estudos de Berrangé (1975); Schaefer e Dalrymple (1996); Cremon et al. (2016), que argumentam evidências geomorfológicas de conexão entre as bacias do rio Branco, no qual o rio Maú teria sido tributário e o rio Essequibo.

Os aspectos geomorfológicos interpretados pelas feições de depósitos recentes e paleocanais distributivos, reforçam a ideia de que ocorreu a formação de sistemas 
de leques aluviais. Com base na interpretação de perfis topográficos longitudinais e transversais, extraídos do MDE ALOS, a variação morfológica das feições apresenta padrões comprobatórios da formação dos leques (Figura 3), conforme discutido nos modelos de Corradani e Assine (2012); Nichols e Fisher (2007); Nichols (2009); Chakraborty e Ghosh (2010).

Os perfis longitudinais PTL-1, PTL-2 e PTL-3 (Figura 3), apresentam uma suave superfície rebaixada em relação ao canal principal do rio Maú que possui cotas na área próxima aos $95 \mathrm{~m}$ de altitude. Os sistemas ramificados de paleocanais se distribuem na superfície com uma suave inclinação, percorrendo cotas entre 90 e $80 \mathrm{~m}$ de altitude. Chama a atenção o fato de que as feições de paleocanais e depósitos aluvionares se estendem num raio de $28 \mathrm{~km}$ de extensão, caracterizando a morfometria deposicional longitudinal dos leques. Já na análise dos perfis transversais PTT-1 e PTT-2 (Figura 3), a morfologia dos lobos deposicionais fica mais evidenciada.
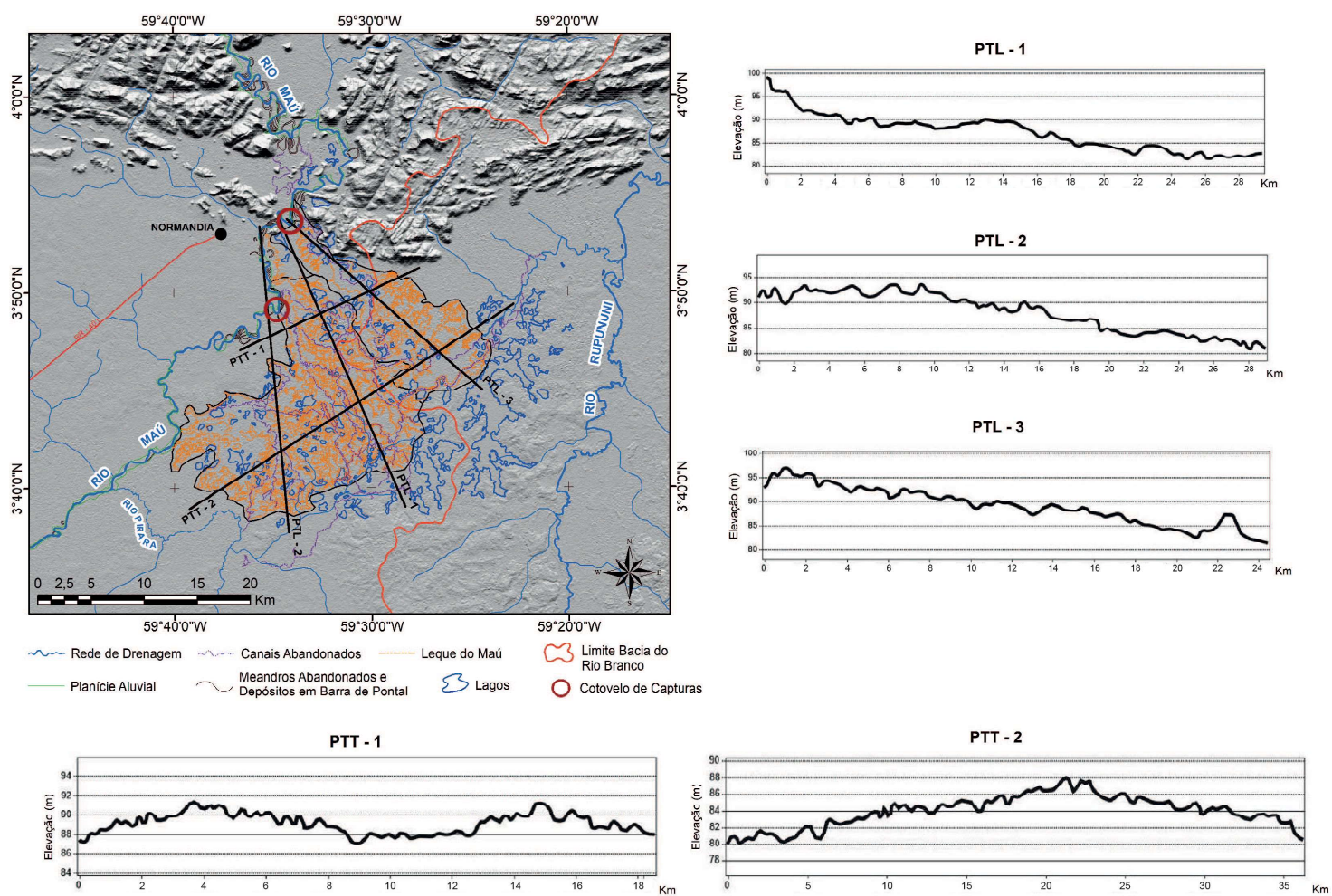

Figura 3 - Imagem sombreada ALOS, com detalhe para as morfologias do leque aluvionar do rio Maú. Detalhe para os perfis transversais PTT-1 e PTT-2, em conjunto com os perfis longitudinais PTL-1, PTL2 e PTL-3, com exagero vertical $4 x$.

Segundo Zani et al., (2009), estas feições alongadas expressam um padrão de sedimentação, elaborado por rede de drenagem distributária, onde ocorre a construção e abandono de depósitos sedimentares. Ao longo do perfil, na parte mais elevada, o canal principal com o fluxo concentrado tem seus diques marginais rompidos. Ao romper os diques, novos canais são entalhados e estes se ramificam formando depósitos distributivos em forma de lobos deposicionais. Esta análise morfológica propicia o entendimento de que com a ramificação dos paleocanais distributivos, o processo de deposição avançava. Contudo, a migração lateral destes canais, proporcionava o abandono dos lobos, reconfigurando o processo de deposição dos leques.

Ao longo do trecho do médio/baixo curso do rio Maú, depósitos sedimentares fluviais como barras de pontal e feições morfológicas de meandros abandonados, indicam a diminuição de sua competência energética, pois o canal flui por um vale entulhado e com suave desnível altimétrico. Associados aos depósitos ocorrem palocanais de drenagem distributárias, formando depósitos em leques aluviais. Vale ressaltar que a distribuição e ramificação da complexa rede de paleocanais e seus depósitos associados sugere um entendimento em duas fases distintas (Figura 4). A fase QF1, assim denominada, apresenta uma rede organizada de paleocanais 
de drenagem conectados diretamente com um afluente do rio Rupununi. Nesta fase, o processo de ruptura dos diques marginais e trasbordamento lateral nos canais não foi constante, sugerindo um equilíbrio momentâneo. A fase QF2, por outro lado, apresenta a maior complexidade na distribuição dos paleocanais, mas mantém a conexão com o tributário do rio Rupununi. $\mathrm{O}$ período compreendido pela fase QF2 corresponde com as abordagens discutidas por Corradani e Assine (2012); Nichols e Fisher (2007); Nichols (2009); Chakraborty e Ghosh (2010), no qual a presença das feições alongadas, lobos, é resultante de um fluxo concentrado em canais distributários.
Possivelmente, com uma mudança no nível de base do canal principal do rio Maú, o lobo aluvionar QF1 sofreu abandono. Este processo acelerou a reorganização da rede de canais, favorecendo então o surgimento do lobo QF2. O perfil topográfico A-B (Figura 4) exemplifica os dois momentos distintos e suas características principais. As evidências inferidas quanto a este processo denotam que devido a um provável rebaixamento do nível de base regional na bacia do rio Branco, todos seus tributários ao norte sofreram influência direta. O input energético pode ser identificado com a presença de cotovelos de capturas no canal principal do rio Maú, próximo aos sitemas QF1 e QF2 (Figura 4).
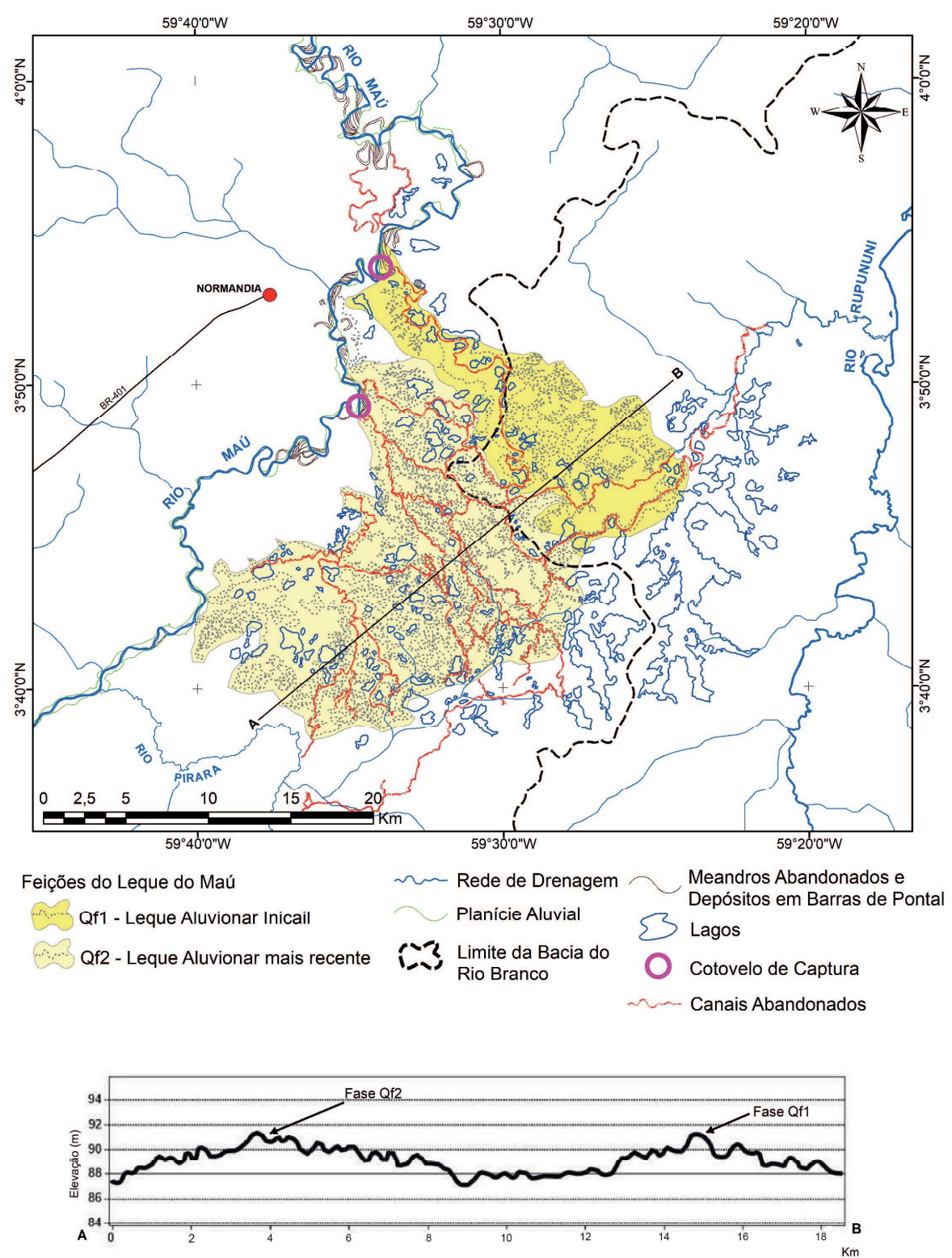

Figura 4 - Modelo evolutivo de feições geomorfológicas de leques aluvionares no médio/baixo curso do rio Maú. Detalhe para o perfil transversal A-B com a fazes de deposição Qf1 e Qf2, com exagero vertical $4 x$. 
As evidências apontam para uma reorganização dos sistemas de paleocanais distributários por migração lateral, favorecendo o abandono dos lobos aluvionares e consequentemente, a comunicação com a bacia do rio Essequibo. Estas evidencias demostram com clareza que o sistema fluvial do alto/médio curso da bacia do rio Branco teria comunicação com a bacia do rio Essequibo, corroborando com as discussões de Berrangé (1975); Schaefer e Dalrymple (1996); Cremon et al. (2016). Indicam ainda que os últimos estágios desta comunicação seriam a captura total da bacia do rio Maú, tendo como produto a presença de feições de leques aluvionares.

\section{Conclusão}

A caracterização morfológica baseada em sensoriamento remoto e análise de dados altimétricos multifontes, levou a conclusão que o sistema hidrográfico do rio Máu apresentava no seu médio/baixo curso morfologias de canais distributários com comunicação com um tributário do rio Rupununi na bacia hidrográfica caribenha do rio Essequibo (Guiana). Estes se organizavam como leques aluvionares, cuja formação é entendida por fluxos provenientes do transbordo e ruptura dos diques marginais dos canais principais, constituindo feições de lobos de sedimentos depositados ao longo das planície aluvial. Uma aparente mudança no nível de base regional do rio Branco favoreceu a captura do rio Maú para a Bacia Hidrográfica Amazônica. Em decorrencia deste fato, os fluxos de deposição são interpretados em momentos distintos, sendo abandonados pela captura final do rio Maú pela bacia do rio Branco. Tais conclusões abrem espaço para estudos futuros que visem datar os depósitos sedimentares e assim remontar a idade dos sistemas de leques e da captura da região drenada pelo rio Maú para a bacia Amazônica.

\section{Agradecimentos}

Os autores gostariam de agradecer ao Laboratório de Geografia Física da Faculdade de Letras da Universidade do Porto/Portugal em conjunto com o Centro de Estudos de Geografia e Ordenamento do Território (CGOT - UP/PT), pelo uso de suas instalações. Agradecem ainda ao Projeto CAPES COFECUB 869/15 pelo apoio.

\section{Referências Bibliográficas}

ALMEIDA, F. F. M. A Evolução dos Crátons Amazônico e do São Francisco, comparada com a de seus Homólogos do Hemisfério Norte. In: Congresso Brasileiro de Geologia, 30. Anais. SBG. v. 6. Recife, 1978. p. 2393- 2407.

BARBOSA, R. I. (1997). Distribuição das Chuvas em Roraima. In: BARBOSA, R. I.; FERREIRA, E. J. G.; CASTELLÓN, E. G. (Eds.) Homem, Ambiente e Ecologia no Estado de Roraima. Ed. INPA. Manaus, p. 325-335.

BERRANGÉ, J. P. The Geomorphology of Southern Guyana with Special Reference to the Development of Planation Surfaces. In: Conferência Geológica Interguianas. Departamento Nacional da Produção Mineral. Anais... Belém, 1975. p. 804-824.

BESERRA NETA, L. C.; TAVARES JÚNIOR, S. S. (2008). Geomorfologia do Estado de Roraima por Imagens de Sensores Remotos. In: SILVA, P. R. F.; OLIVEIRA, R. S. (Org.) Roraima 20 Anos: As Geografias de um Novo Estado. Ed. UFRR. Boa Vista,. p. 168-192.

BISHOP, P. Drainage Rearrangement by River Capture, Beheading and Diversion. Progress in Physical Geography, v. 19, n. 4, p. 449-473, 1995.

CHAKRABORTY, T.; GHOSH, P. The Geomorphology and Sedimentology of the Tista Megafan, Darjeeling Himalaya: Implications for Megafan Building Processes. Geomorphology, v. 115, n. 3-4, p. 252-266, 2010.

CORDANI, U. G.; TEIXEIRA, W. Proterozoic Accretionary Belts in the Amazonian Craton. Geological Society of America Memories. v. 200, p. 297-320. 2007

CORRADINI, F. A.; ASSINE, M. L. Compartimentação Geomorfológica e Processos Deposicionais no Megaleque Fluvial do rio São Lourenço, Pantanal Mato-Grossense. Revista Brasileira de Geociência. v. 42 (Suplem. 1), p. 20-33. 2012.

COSTA, J. A. V. (2008). Compartimentação do Relevo do Estado de Roraima. In: OLIVEIRA, R. S. (Org.); Roraima em Foco: Pesquisas e Apontamentos Recentes. Ed. da UFRR. Boa Vista, p. 77-107.

COSTA, J. B. S.; PINHEIRO, R. V. L.; REIS, N. J.; PESSOA, M. R.; PINHEIRO, S. S. O Hemigraben do Tacutu: uma Estrutura Controlada pela Geometria do Cinturão de Cisalhamento Guiana Central. Geociências. Vol. 10. São Paulo, 1991. p. 119-130.

CPRM - Serviço Geológico do Brasil. Programa Levantamentos Geológicos Básicos do Brasil. Roraima Central, Folhas NA.20X-B e NA.20-X-D (integrais), NA.20-X-A, NA.20-X-C, 
NA.21-V-A e NA.21-V-C (parciais). Escala 1:500.000. Estado de Roraima. Superintendência Regional de Manaus. Manaus, 1999. 166p.

CREMON, E. H.; ROSSETTI, D. F.; SAWAKUCHI, A. O.; COHEN, M. C. L. The role of tectonics and climate in the late Quaternary evolution of a northern Amazonian River. Geomorphology. v. 271. Sciencedirect. Amsterdã, 2016. p. 22-39.

EVANGELISTA, R. A. O.; SANDER, C.; WANKLER, F. L. (2008). Estudo Preliminar da Distribuição Pluviométrica e do Regime Fluvial da Bacia do Rio Branco. In: SILVA, P. R. F.; OLIVEIRA, R. S. (Org.) Roraima 20 Anos: As Geografias de um Novo Estado. Ed. UFRR. Boa Vista,. p. 142-167.

GUERRA, A. T. Estudo Geográfico do Território Federal de Roraima. Rio de Janeiro, IBGE-Instituto Brasileiro de Geografia e Estatística, 1957. 252p.

GUPTA, A. (Ed.). Large Rivers: Geomorphology and Management. Wiley, Chichester, 2007. 689p.

HAHN, P. Y. S.; TAVARES JÚNIOR, S. S.; BESERRA NETA, L. C. Estudos Tectono-estrutural na Bacia do Tacutu-RR por meio de Fotointerpretação Geológica em Imagens Digitais do Sensor Ópitico CCD/CBERS 2B e Levantamento em Campo. $12^{\circ}$ Simpósio de Geologia da Amazônia, Anais... vol. digital. Boa Vista, 2011.

HASUI, Y.; HARALYI, N. L.; SCHOBBENHAUS C. Elementos Geofísicos e Geológicos da Região Amazônica: Subsídios para o Modelo Geotectônico. Simp. Amaz.. v2. Anais... Manaus, 1984. p. 129-147.

HUGGET, R. J. Fundamentals of Geomorphology. Second ed. London: Taylor and Francis, 2007. 458p.

IBGE - Instituto Brasileiro de Geografia e Estatística. Mapa Geomorfológico do Estado de Roraima. Diretoria de Geociências

- Coordenação de Recursos Naturais e Estudos Ambientais. $1^{\text {a }}$ Ed. Rio de Janeiro, 2005. Escala 1:1.000.000

MARZOLI, A.; RENNE, P. R.; PICCIRILLO, E. M,; ERNESTO, M.; BELLIENE, G.; DE MIN, A. Extensive 200-Million-YearOld Continental Flood Basalts of the Central Atlantic Magmatic Province. Science, n. 284, 1999. p. 616-618.

NASCIMENTO, S. O. Compartimentação Geomorfológica do Gráben do Tacutu, centro-nordeste de Roraima. Dissertação (Mestrado em Geografia). Instituto de Geociências. Universidade Federal de Roraima. 2016. 120p.

NICHOLS, G. J.; FISHER, J. A. Processes, Facies and Architecture of Fluvial Distributary System Deposits. Sedimentary Geology, v. 195, n. 1-2, 2007. p.75-90.
NICHOLS, G. (2009). Sedimentology and stratigraphy. John Wiley \& Sons. 450p.

PEDERSON, D. T. Stream Piracy Revisited: A GroundwaterSapping Solution. GSA Today, v. 11, n. 9, 2001. p. 4-10.

PRINCE, P. S., SPOTILA, J. A.; HENIKA, W. S. New Physical Evidence of the Role of Stream Capture in Active Retreat of the Blue Ridge Escarpment, Southern Appalachians. Geomorphology, v. 123, n. 3-4. 2010, p.305-319.

RABUS, B.; EINEDER, M.; ROTH, A.; BAMLER, R. The Shutlle Radar Topography mission - a new class of digital elevations models acquired by Spaceborne Radar. Journal of Photogrammetry e Remote Sensing. n 57, 2003. p.241-262.

REIS N. J.; FARIA M. S. G.; FRAGA, L. M. B.; HADDAD, R. C. Orosirian Calc-Alkaline Volcanism and the Orocaima Event in the Northern Amazonian Cráton, Eastern Roraima State, Brazil. Rev. Bras. Geociências. v. 30, n 3, 2000. p.380-383.

REIS, N. J.; FRAGA, L. M.; FARIA, M. S. G.; ALMEIDA, M. E. Geologia do Estado de Roraima. Géologie de la France. v. 2-3, 2003. p.71-84.

SCHAEFER, C. E.; DALRYMPLE, J. Pedogenesis and relict properties of soils with columnar structure from roraima, north amazonia. Geoderma. v. 71, n. 1-2, 1996. p. 1-17.

SILVA, E. L. (1997). A Vegetação de Roraima. In: BARBOSA, R. I.; FERREIRA, E. J. G.; CASTELLÓN, E. G. (Eds.) Homem, Ambiente e Ecologia no Estado de Roraima. Ed. INPA. Manaus. v 01, p.401-415.

STEVAUX, J. C.; LATRUBESSE, E. M. (2017). Geomorfologia fluvial. Oficina de Textos, v1, Rio de Janeiro. 250p.

SUMMERFIELD, M. A. (1991). Global geomorphology: an introduction to the study of landforms. New York: Longman, $537 \mathrm{p}$.

TASSINARI, C. G. C.; MACAMBIRA, M. J. B. (2004). A evolução tectônica do Cráton Amazônico. In: NETO-MANTESSO, V.; BARTORELL, A.; CARNEIRO; C.D.R. \& BRITONEVES, B.B. DE (Eds.). Geologia do Continente Sulamericano. São Paulo: Editora Beca, p.471-486.

VALERIANO, M. M. (2008). TOPODATA: Guia de Utilização de Dados Geomorfológicos Locais. Instituto Nacional de Pesquisas Espaciais - INPE. v 01. São José dos Campos. 75p.

ZANI, H.; ASSINE, M. L.; SILVA, A.; CORRADINI, F. A. Redes de Drenagem Distributária e Formas Deposicionais no Megaleque do Taquari, Pantanal: uma análise baseada no MDE-SRTM. Revista Brasileira de Geomorfologia, v. 10, n. 2, 2009. p.21-28. 